\title{
STUDY OF PHYSICAL ACTIVITY AND DIETARY INTERVENTIONS FOR WEIGHT MANAGEMENT BEFORE PREGNANCY OF BULGARIAN WOMEN
}

\author{
Diana Popova-Dobreva \\ National Sports Academy "Vassil Levski”, Sofia, Bulgaria
}

\begin{abstract}
The rise in obesity and associated morbidity is currently one of our greatest public health challenges. Women represent a high-risk group for weight gain with associated metabolic, cardiovascular, reproductive and psychological health impacts. Regular physical activity is fundamental for health and well-being with protective benefits across the spectrum of women's health (Harrison, 2016).

A survey was conducted with 717 Bulgarian women between 19 and 35 years of age. The purpose of the study is to determine advice and support for weight control before pregnancy. Characteristic of women is made by age, BMI and occupation. Twenty-one percent of women surveyed fall into the category of those with overweight BMI, and $11 \%$ were obese.

A discussion was held on the level of women's awareness and professional support. The investigated women have done a self-assessment of their physical activity before their last pregnancy. Women's questions are related to information about the risks to them and their child in the presence of overweight; have any weight loss tips or opportunity to join a weight loss group; have attended a physiotherapist before, during or after pregnancy. The results presented in this article are part of the overall study, including issues related to pregnancy and after birth.

We believe that advice on appropriate exercise, with appropriate intensity, dosage, rate frequency of performance is important to weight management before, during and after pregnancy and it necessary to include physiotherapists and nutritionists in the process of weight management, and this to be a state policy to promote health.
\end{abstract}

Key words: weight management, pregnancy, physical activity, dietary interventions.

\section{INTRODUCTION}

Normal body weight is essential for human health. Deviations both in terms of weight loss and weight gain affect the health of people. Weight control in women of reproductive age who are about to become pregnant and giving birth provides favorable conditions for pregnancy, childbirth and recovery in the postpartum period.

Ozdilek R et al. aim to investigate the adaptation of pregnant women to the recommended weight gain range according to body mass index (BMI) and to determine the factors affecting them. They have investigated eight hundred twelve pregnant women with normal antenatal follow-up and who volunteered to participate were included in the study. The authors conclude that the groups with overweight and obese pregnant women according to BMI before pregnancy had the highest rates of weight gain, above the recommended limits. BMI before pregnancy directly affects weight gain during pregnancy and the importance of pre-pregnancy counseling and weight loss is emphasized once again (Ozdilek et al., 2019).

A series of studies have focused on the risks associated with pre-pregnancy pregnancy (Zhao, Zhou, Zhang, 2019; Munda et al., 2019; Msollo et al., 2019; Wang et al. 2019;)

Regular physical activity and healthy eating are at the heart of weight management. It is important for women of reproductive age to be specifically informed about the risks associated with being overweight, both for themselves and for their offspring. Health professionals should be committed to promoting a healthy lifestyle.

Many authors study lifestyle interventions targeting diet, physical activity, and behavioral strategies in women with overweight and obesity who are about to become pregnant and giving birth (Phelan et al, 2018; Tanentsapf et al, 2011; Oteng-Ntim et al, 2012; Jiang et al, 2012; Kunath et al, 2019)

The conception of this study is to determine the extent to which Bulgarian healthcare professionals are focusing the attention of women of reproductive age on the possibilities for weight management. 
Aim of the study

The purpose of this study is to determine the extent to which Bulgarian women are informed about the health risks associated with being overweight and whether Bulgarian health professionals are focusing women's attention on the problem.

\section{METHODS}

A survey was conducted with 717 women aged 19 to 35 through a Facebook marketing study. A standardized questionnaire "Weight management before, during and after pregnancy", National Insti- tute for Health and Clinical Excellence, 2010 was used (https://www.nice.org.uk.)

The results presented in this article are part of the overall study, including issues related to women of reproductive age who are about to become pregnant and giving birth.

The studied group was characterized by parity, level of education and physical activity prior to their last pregnancy. The results of the study are presented by frequency analysis.

\section{RESULTS}

\section{PARITY $(\mathbf{N}=717)$}

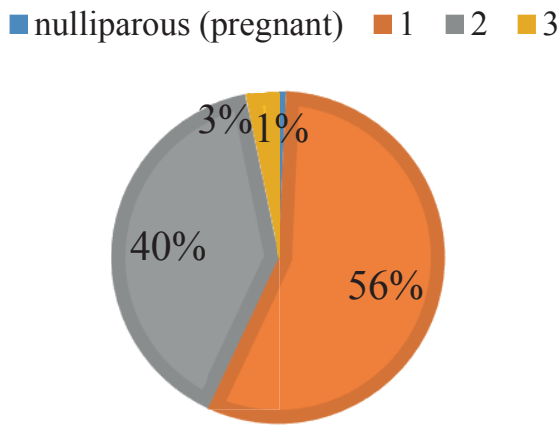

Figure 1. Parity

Figure 1 shows a characteristic of the parity con- first child. Three percent of the surveyed contingent tingent. The majority of women (56\%) gave birth of 717 Bulgarian women gave birth 3 times. once, $40 \%$ gave birth twice, $1 \%$ are expecting their

\section{LEVEL OF EDUCATION (N=717)}

- Lower secondary education $\quad$ Upper secondary education
$\square$ Bachelor's degree/Master's degree $\square$ Doctoral degree $(\mathrm{PhD})$

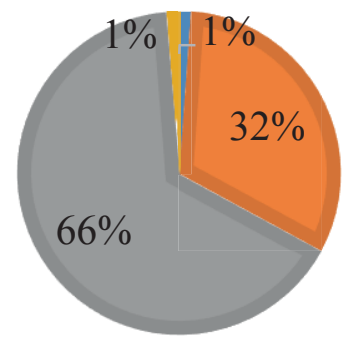

Figure 2. Level of education

Of the surveyed contingent, $66 \%$ had bachelor's and well-educated women in this type of study. The remaster's degrees, followed by $32 \%$ women with sec- sults support our personal observation that women ondary education. It is expected for us to include seeking information are well educated. 


\section{PHYSICAL ACTIVITY (N=717)}

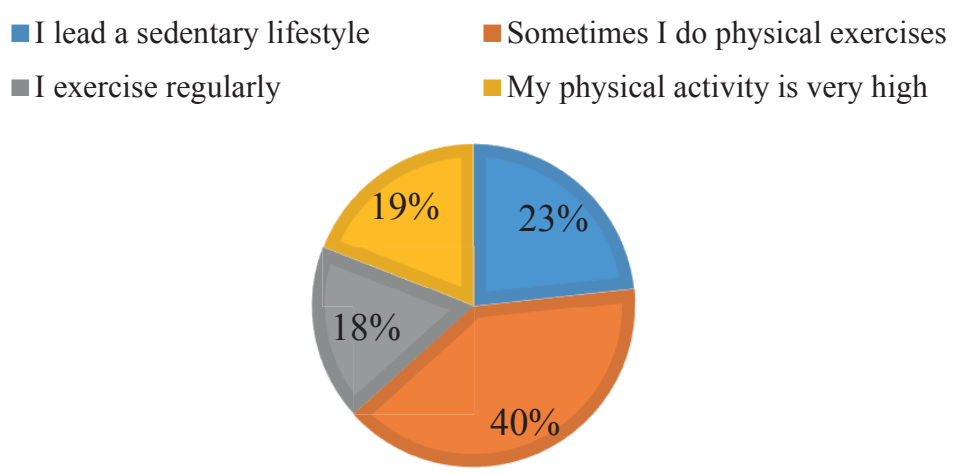

Figure 3. Physical activity

Contingent women most often performed irregular $18 \%$ of women exercise regularly. The results dephysical activity (40\%). An alarmingly high per- monstrate a well-known modern trend towards a centage of women are leading a sedentary lifestyle sedentary lifestyle that has proven to have a nega(23\%) or one with very low physical activity. Only tive effect on people's health.

\section{INFORMATION ABOUT THE RISKS OF OVERWEIGHT $(\mathrm{N}=717)$}

-Yes $\quad$ No $\quad$ I do not remember

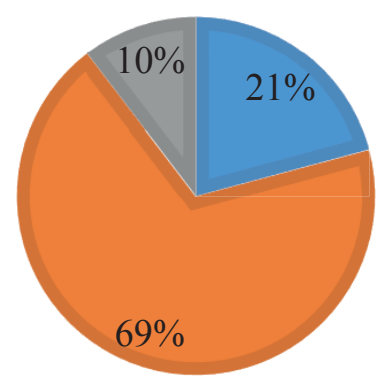

Figure 4. Information on the risks of overweight

The question is "When you were planning to have receive information regarding the health risks assoa child, did you receive information from your he- ciated with being overweight. The results demonstalthcare provider or other healthcare professional rate the lack of organized promotion of healthy lifeabout what risks are there for you and your child if styles in Bulgarian society. The results shown in the you are overweight?". following two figures are also supporting this trend.

Two thirds of the women surveyed (69\%) did not

\section{ADVICE TO INCLUDE IN THE WEIGHT LOSS GROUP $(\mathrm{N}=717)$}

Yes No $\quad$ I do not remember $\quad$ I didn't need it

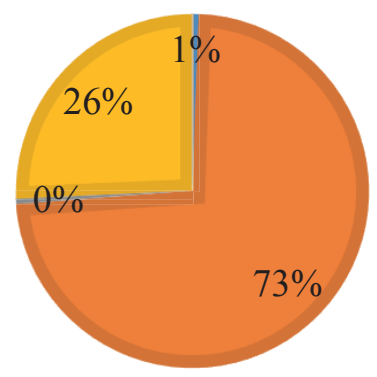

Figure 5. Advice to include in the weight loss group 
$73 \%$ of women surveyed were not advised to seek specialist help from a physiotherapist or other health care professional for weight loss. From the results presented in a previously related study, 30\% were overweight and obese before their last pregnancy.

\section{ADVICE HOW TO LOSE WEIGHT BEFORE PREGNANCY $(\mathrm{N}=717)$}

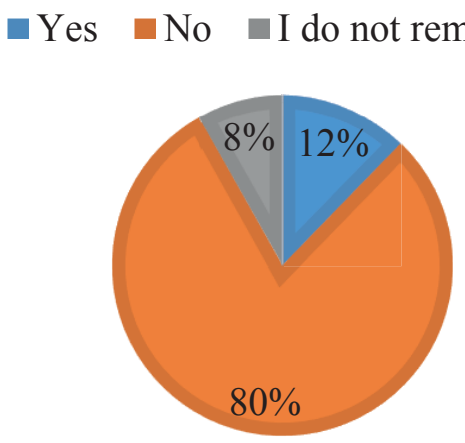

Figure 6. Advice how to lose weight before pregnancy

The question is "Do you think you have received helpful tips on how to lose weight before pregnancy?" Most of the women of reproductive age from the study contig were not informed how they could control their body weight $(80 \%)$. The results correspond to the above.

\section{DISCUSSION}

According to Ma RCW et al. (2016) the global epidemic of obesity has led to an increasing number of obese women of reproductive age. Obesity is associated with reduced fertility, and pregnancies complicated by maternal obesity are associated with adverse outcomes, including increased risk of gestational diabetes, pre-eclampsia, preterm birth, instrumental and caesarean births, infections, and post-partum hemorrhage. The medical and obstetric management of obese women is focused on identifying, addressing, and preventing some of these associated complications, and is a daunting challenge given the high percentage of patients with obesity and few therapeutic options proven to improve outcomes in this population.

An analysis of 20 studies involving 11,444 women revealed that diet or exercise, or both, during pregnancy can reduce the risk of excessive GWG. Other benefits may include a lower risk of caesarean delivery, macrosomia, and neonatal respiratory morbidity, particularly for high-risk women receiving combined diet and exercise interventions. Maternal hypertension may also be reduced. Exercise appears to be an important part of controlling weight gain in pregnancy and more research is needed to es- tablish safe guidelines. Most included studies were carried out in developed countries and it is not clear whether these results are widely applicable to lower income settings (Muktabhant et al., 2015).

The following trends emerge from our study, and in particular the results commented in this article:

- Most well-educated Bulgarian women give birth once or twice;

- The physical activity of Bulgarian women of reproductive age is definitely insufficient;

- There is a lack of information system for Bulgarian women of reproductive age about the risks of being overweight and how to handle it.

- Bulgarian specialists in the area are aware of the fact that women of reproductive age (and not only them) are not organized in a supportive way to lead a healthy lifestyle. Moreover, this study demonstrates that health care professionals have not even drawn women's attention to this issue. According to Committee on Obstetric Practice regular physical activity in all phases of life, including pregnancy, promotes health benefits. Pregnancy is an ideal time for maintaining or adopting a healthy lifestyle and the American College of Obstetricians and Gynecologists makes the specific recommendations (https://www.acog.org).

We consider it necessary to introduce such good practices in Bulgaria. It is even more important to create conditions for organized physical activity of Bulgarian women of reproductive age. 


\section{REFERENCES}

Jiang, H., Qian, X., Li, M., Lynn, H., Fan, Y., Jiang, H., He, F., He, G. (2012). Can physical activity reduce excessive gestational weight gain? Findings from a Chinese urban pregnant women cohort study. Int J Behav Nutr Phys Act. 2012 Feb 9; 9:12. doi: 10.1186/1479-5868-9-12. Kunath, J., Günther, J., Rauh, K., Hoffmann, J., Stecher, L., Rosenfeld, E., Kick, L., Ulm, K., Hauner, H. (2019). Effects of a lifestyle intervention during pregnancy to prevent excessive gestational weight gain in routine care - the cluster-randomised GeliS trial. BMC Med. Jan 14; 17(1):5.

Ma, RCW., Schmidt, MI., Tam, WH., McIntyre, HD., Catalano, PM. (2016). Clinical management of pregnancy in the obese mother: before conception, during pregnancy, and post-partum, Lancet Diabetes Endocrinol. 2016 Dec; 4(12): 1037-1049.

Oteng-Ntim, E., Varma, R., Croker, H., Poston, L., Doyle, P. (2012). Lifestyle interventions for overweight and obese pregnant women to improve pregnancy outcome: systematic review and meta-analysis. BMC Med. 2012 May 10;10:47. doi: 10.1186/1741-7015-10-47. Review.

Ozdilek, R., Aba, YA., Aksoy, SD., Sik, BA., Akpak, YK. (2019). The relationship between body mass index before pregnancy and the amount of weight that should be gained during pregnancy: A cross-sectional study. Pak J Med Sci. 2019 Sep-Oct;35(5):1204-1209.

Phelan, S., Wing, RR., Brannen, A., McHugh, A., Hagobian, TA., Schaffner, A., Jelalian, E., Hart, CN., Scholl, TO., Munoz-Christian, K., Yin, E., Phipps, MG., Keadle, S., Abrams, B. (2018). Randomized controlled clinical trial of behavioral lifestyle intervention with partial meal replacement to reduce excessive gestational weight gain. Am J Clin Nutr. 2018 Feb 1; 107(2) pp.183-194.

Popova $\square$ Dobreva, D., (2018). Study of physical activity and dietary interventions for weight management during pregnancy of Bulgarian women, Bulletin of the Transilvania University of Braşov Series IX: Sciences of Human Kinetics. Vol. 11 (60) No. $1 \square 2018$

Muktabhant, B1., Lawrie, TA., Lumbiganon, P., Laopaiboon, M. (2015). Diet or exercise, or both, for preventi- ng excessive weight gain in pregnancy. Cochrane Database Syst Rev. 2015 Jun 15;(6):CD007145.

Munda, A., Starčič Erjavec, M., Molan, K., Ambrožič Avguštin, J., Žgur-Bertok, D., Pongrac Barlovič, D. (2019). Association between pre-pregnancy body weight and dietary pattern with large-for-gestational-age infants in gestational diabetes. Diabetol Metab Syndr. 2019 Aug $22 ; 11: 68$.

Msollo, SS., Martin, HD., Mwanri, AW., Petrucka, P. (2019). Prevalence of hyperglycemia in pregnancy and influence of body fat on development of hyperglycemia in pregnancy among pregnant women in urban areas of Arusha region, Tanzania. BMC Pregnancy Childbirth. 2019 Aug 28;19(1):315. doi: 10.1186/s12884-019-2463-8.

Tanentsapf, I., Heitmann, BL., Adegboye, AR. (2011). Systematic review of clinical trials on dietary interventions to prevent excessive weight gain during pregnancy among normal weight, overweight and obese women. BMC Pregnancy Childbirth. 2011 Oct 26; 11:81.

Zhao, RF., Zhou, L., Zhang, WY. (2019). Identifying appropriate pre-pregnancy body mass index classification to improve pregnancy outcomes in women of childbearing age in Beijing, China: a retrospective cohort study. Asia Pac J Clin Nutr. 2019; 28(3):567-576.

Wang, X., Zhang, X., Zhou, M., Juan, J., Wang, X. (2019). Association of pre-pregnancy body mass index, rate of gestational weight gain with pregnancy outcomes in Chinese urban women. Nutr Metab (Lond). 2019 Aug 19; 16:54. doi: 10.1186/s12986-019-0386-z. eCollection. https://www.nice.org.uk (accessed 12 December 2017) https://www.acog.org/Clinical-Guidance-and-Publications/Committee-Opinions/Committee-on-Obstetric-Practice/Physical-Activity-and-Exercise-During-Pregnancy-and-the-Postpartum-Period?IsMobileSet=false (accessed 02 February 2018)

Corresponding author:

Diana Popova-Dobreva, PhD,

Associate Professor National Sports Academy "Vassil Levski" 1000 Sofia, Bulgaria E-mail: dobreva_da@yahoo.com 